\title{
Mercados financeiros eletrônicos: características culturais, relações sociais e instrumentos financeiros na tomada de decisão dos corretores de valores
}

\author{
Thiago de Sousa Barros ${ }^{1}$ \\ Pedro Otávio de Campos Andrade ${ }^{2}$
}

\begin{abstract}
Resumo: Esta pesquisa, conduzida pela ótica da chamada "Nova Sociologia Econômica", investiga a ação dos corretores de valores, com ênfase nas suas características profissionais, culturais, bem como nas relações sociais mantidas. Dessa feita, por meio de análise documental e de vinte entrevistas estruturadas, realizadas em 2018, no próprio ambiente de trabalho dos referidos operadores, este estudo tem cariz qualitativo e traz contribuições importantes para que se possa compreender a atuação desses agentes considerados fundamentais nos mercados financeiros eletrônicos. Em suma, este artigo examina de que maneira o processo decisório dos corretores constrói uma nuvem de palavras e uma sólida análise de sentimentos, com base no perfil das atividades exercidas, amalgamando as predileções por determinados instrumentos financeiros de análise no ato de comprar e vender ações. Os resultados mostram que as redes sociais estabelecidas entre profissionais da área são de vital importância para o processo decisório e que a ferramenta mais utilizada no cotidiano dos corretores é a análise gráfica (técnica). Desse modo, as análises fundamentalistas, macroeconômicas e estimações econométricas são relegadas a um plano menor. Por outro flanco analítico, nota-se que o corretor incorrerá em conflitos de interesses, pois objetiva maximizar taxas de corretagem (comissões) e pode indicar para os investidores "girar" o portfólio constantemente. A nuvem de palavras mostrou, ademais, que os entrevistados comparam, de forma recorrente, nuances dos mercados financeiros eletrônicos atuais com os tempos de pregão viva-vOz e fazem uso constante de termos das finanças ao longo do discurso. Com relação à análise dos sentimentos, observa-se prevalência de animosidade entre corretores de valores, um comportamento que capta o otimismo desses atores em relação ao crescimento vertiginoso do mercado de capitais no país. Por fim, compreende-se que a cultura dos corretores de valores do Brasil, especialmente da cidade de Belo Horizonte, converge para a realidade de outros países e mercados financeiros pesquisados por autores da área de finanças sociais.
\end{abstract}

Palavras-chave: Nova Sociologia Econômica. Corretores de valores. Análise financeira. Relações sociais. Tomada de decisão.

\section{Electronic financial markets: cultural characteristics, social relations and financial instruments in the decision making of stockbrokers}

\begin{abstract}
This research, conducted from the perspective of the so-called "New Economic Sociology", investigates stockbrokers, with an emphasis on the professional and cultural characteristics of these fundamental agents in the electronic financial markets. This time, through documentary analysis and twenty structured interviews, carried out in 2018 and in the work environment of these operators, this study has a qualitative nature and brings important contributions to analyze this segment of society. In short, this article analyzes the decision-making process of these brokers, builds a word cloud and builds a solid analysis of feelings, based on the profile of the activities they carry out, amalgamating the predilections for certain financial instruments of analysis in the act of buying and selling shares, as well as the cultural characteristics of the profession and the social relationships maintained by these individuals.

\footnotetext{
${ }^{1}$ Doutor em Administração de Empresas pela Fundação Getúlio Vargas (EAESP). Professor Adjunto na Universidade Federal de Ouro Preto. E-mail: tsousabarros@gmail.com.

${ }^{2}$ Graduando em Relações Econômicas Internacionais na UFMG. Assistente de Pesquisa na FACE/UFMG. E-mail: pedroandrade.ufmg@gmail.com.
} 
The results indicate that the social networks established among professionals in the area are of vital importance in the decision-making process and that the most used tool in the daily lives of brokers is the graphical (technical) analysis, with fundamentalist, macroeconomic and econometric estimates being relegated to a plan smaller. On the other hand, it is noted that the broker will incur conflicts of interest, as it aims to maximize brokerage fees (commissions) and can indicate to investors to "rotate" the portfolio constantly. In addition, the word cloud showed that respondents repeatedly compare nuances of the current electronic financial markets with the times of the open floor and make constant use of finance terms throughout the speech. Regarding the analysis of feelings, there is a prevalence of animosity behavior among stockbrokers, emotions that capture the optimism of these actors with the dizzying growth of the capital market in the country. Finally, it is understood that the culture of Stockbrokers in Brazil, especially in the city of Belo Horizonte, converges to the reality of other countries and financial markets already researched by authors in the area of social finance.

Keywords: New Economic Sociology. Stockbrokers. Financial analysis. Social relationships. Decisionmaking.

\section{Introdução}

Nos últimos anos tem ocorrido um crescimento vertiginoso, na esfera internacional e pela ótica antropológica e sociológica, da literatura que retrata os mercados financeiros, compreendida como estudos sociais das finanças. Os mercados financeiros em si são tema de estudo há mais de cem anos, mas, somente nos últimos dez, emergiu o interesse pela abordagem cultural, sociológica, histórica e institucional desse tipo de mercado.

Diversas pesquisas vêm sendo conduzidas nessa área, o que enfatiza o grau de maturidade do assunto (BEUNZA e STARK, 2004; MAURER, 2005; ZALOOM, 2006; PREDA, 2009; PARDOGUERRA, 2010a, 2010b e 2010c; MACKENZIE, 2011a e 2011b; PREDA e KNORR-CETINA, 2012; MIYAZAKI, 2013; BEUNZA e MILLO, 2014). Há, no entanto, certa prevalência de estudos em países europeus e asiáticos, bem como nos Estados Unidos da América. No Brasil, Grün (2010 e 2013) e Müller (2002, 2003, 2004 e 2005) concentraram-se na Bolsa de Valores de São Paulo, mas conduziram estudos que investigaram, a priori, as perspectivas institucionais e normativas, relegando a dinâmica cultural e dos processos de trabalho dos corretores a um segundo plano, especialmente no período de transformações observado: pós-digitalização e incorporação de inovações tecnológicas aos mercados financeiros

Não obstante, e considerando as proposições de Pardo-Guerra (2014, p.8), que considera "os mercados financeiros como sistemas sociais densos, caracterizados por sistemas simbólicos, práticos e tecnológicos específicos que servem como as infraestruturas sobre as quais circula o capital”, esta pesquisa poderá contribuir para uma visão plural desse mercado considerado essencial para as economias internacionais e, mediante uma pesquisa que contempla a socioantropologia econômica, construir uma discussão acerca da cultura brasileira nesse segmento.

Em face disso, este artigo parte dos fundamentos teóricos da "Nova Sociologia Econômica" e sua evolução, descreve o advento da digitalização da Bolsa de Valores do país (B3) e apresenta os aspectos culturais, além das características de trabalho dos corretores de valores no Brasil. Como o objetivo principal deste estudo é analisar a realidade prática do processo de tomada de decisão desses indivíduos e a 
influência das ferramentas tecnológicas e das relações sociais nesse meio, desenvolveu-se uma abordagem qualitativa que utiliza como métodos de pesquisa entrevistas estruturadas, análise documental e de sentimentos.

O tema mostra-se de extrema importância para a realidade contemporânea, dado o crescimento vertiginoso do mercado de capitais no Brasil, principalmente diante da redução das taxas de juros no país, levando investidores a assumirem mais riscos e a buscarem a bolsa de valores como principal alternativa para maximizar a rentabilidade de seus investimentos (BONALDI, 2018; CHAGUE e GIOVANNETTI, 2020). Ademais, com essa expansão, há captação de novos entrantes interessados em operações de ações (em especial operando com day trade, isto é, indivíduos que compram e vendem papéis no mesmo dia de forma especulativa, e não com base nos fundamentos das ações, visando investimentos de longo prazo), muitos deles sem informações e formação suficiente para tal (CHAGUE, DE-LOSSO e GIOVANNETTI, 2020). Esse fato corrobora a necessidade de realizar esta pesquisa, a qual permitirá entender o que está por trás da dinâmica de trabalho dos corretores de valores que atuam na B3, com ênfase nos dilemas que perpassam a profissão e tudo que envolve a decisão por comprar ou vender determinada ação.

Outra informação importante, a profissão dos corretores ganhou notoriedade, muito em função das inúmeras perdas financeiras de operadores day traders que trabalham em suas residências, via bome broker (CHAGUE e GIOVANNETTI, 2020), dispensando os serviços profissionais dos agentes autônomos que poderiam auxiliar nesse processo de tomada de decisão. Dessa feita, investigar os meios que os corretores utilizam no ato decisório, com destaque para as ferramentas financeiras de análise de investimentos em ações e as relações sociais estabelecidas, podem contribuir para um nível de compreensão mais aprofundado acerca dos mercados financeiros eletrônicos.

\section{Referencial teórico}

\subsection{A Nova Sociologia Econômica: relações sociais dos agentes e o processo de tomada de decisão}

Estudos demonstram, ao realizar uma perspectiva da evolução das finanças ao longo do tempo, a necessidade de criar vias alternativas de pesquisa nesse terreno de investigação (BRENNAN, 1995; DIMSON E MUSSAVIAN, 1999; JENSEN, 2001; LOBÃO, 2018). Em face desse cenário, novas possibilidades foram delineadas e a integração com outros campos do conhecimento mostrou-se uma vereda assaz relevante, em especial, aqueles que tencionam compreender o comportamento humano e suas nuances, como ocorre, por exemplo, com a Psicologia, a Sociologia e a Antropologia (BARROS, 2017).

Nesse sentido, trabalhos seminais foram desenvolvidos e, mediante uma nova perspectiva, uniram outras áreas às finanças. Kahneman e Tversky (1979) desenvolveram a Teoria do Prospecto e enfatizaram a importância dos atributos psicológicos e cognitivos no processo decisório. Por outro viés analítico, Williamson (1975, 1988 e 1991) integrou conhecimentos de sociologia, economia e finanças, adaptando-os a aspectos de governança econômica. Mais recentemente, Richard Thaler obteve a mesma honraria de 
Kahneman e ganhou o Nobel de Economia, um reconhecimento aos seus trabalhos em economia comportamental, nos quais destacou, principalmente, os erros sistemáticos (tratando as idiossincrasias dos indivíduos não como meros desvios aleatórios) e a teoria do empurrão (THALER, 1991 e 2015; THALER e SUNSTEIN, 2008).

Tais avanços têm uma visão mais aplicada às finanças de um modo geral. Nesse mesmo contexto, porém com outra vertente, surgiu a chamada "Nova Sociologia Econômica", que amalgamou diversas perspectivas teóricas de múltiplas áreas, sendo desenvolvida, segundo Smelser (1963), por economistas, sociólogos e psicólogos da indústria, pesquisadores de antropologia econômica e sociólogos do desenvolvimento econômico. O foco desse campo de pesquisa centra-se em algumas questões: de que maneira as atividades estruturam-se na coletividade? Quais valores as legitimam? Como se constituem as sanções reguladoras? Outro ponto central é compreender a interação das variáveis sociológicas, exaltando as relações causais entre os aspectos econômicos da vida social (SMELSER, 1963).

Conforme Granovetter (1983), considerado fundador da "Nova Sociologia Econômica", a rede social na qual determinado indivíduo está integrado, tem influência nas decisões tomadas por ele, uma vez que o indivíduo pode influenciar ou ser influenciado por essas relações sociais que mantém. Em suma, o sociólogo realça a existência de laços essenciais entre indivíduos (sejam eles fortes ou fracos), conexões fundamentais no processo de circulação de informações, principalmente no mercado financeiro.

A pesquisa de Granovetter (1983) revelou, por meio de dados empíricos, que os laços fracos tendem a apresentar maior eficácia na troca de informações, pois, ao serem estabelecidos, tornam-se primordiais à preservação e à perpetuação dessa rede de contatos (RAUD-MATTEDI, 2005). Quando se levam em consideração a empatia e a afeição entre os agentes, é possível aproximar e consolidar cada vez mais as relações nascidas da troca de informações. Sendo assim, a informação ou inovação favorecerá os demais integrantes da sociedade em rede (GRÜN, 2004a e 2004b).

Steiner (2006) aduz à discussão a tese de que os indivíduos desenvolvem maior percepção quanto às interações entre as redes sociais e à maneira como elas influenciam os mercados. Estes, por sua vez, se caracterizam por qualquer relação que inclua dois agentes ou quando um agente possui grande rede de contatos. Portanto, a sociologia econômica parte de dois pressupostos diferentes, no que tange à evolução do estudo das finanças, tanto com base nos estudos de Polanyi (2001), criador da ideia de construção social dos mercados como porta de entrada, quanto na afirmação da relevância de um ponto de vista sociológico para tais fenômenos, normalmente estudados por economistas (GARCIA, 1986; CALLON, 1998).

O primeiro pressuposto aponta direto para o mercado financeiro, com ênfase nos modelos capitalistas, unidos por sociólogos que se ocupam da discussão em torno da economia e das organizações (GUILLÉN, 1994; HOLLINGSWORTH e BOYER, 1997; STREECK e CROUCH, 1997; GUILLÉN, 2000). Já a linha de estudo das finanças, que prevê a perfeita racionalidade dos agentes financeiros, opõese à linha explicativa de autores da sociologia das finanças (HIRSCH e FRIEDMAN, 1990; KNORRCETINA e BRUEGGER, 2002), os quais tratam do comportamento dos agentes na esfera econômica, com base no processo de adaptação (GRÜN, 2004a). Estes autores não dissertam apenas sobre o 
comportamento dos agentes, mas também sobre artefatos físicos e cognitivos necessários ao avanço e ao bom funcionamento dos instrumentos financeiros, bem como a respeito dos mercados, o que é designado como grande arena social (MACKENZIE e MILLO, 2003).

Os processos de inovação tecnológica nas instituições financeiras constituem toda a infraestrutura utilizada pelos agentes. Desse modo, qualquer alteração mínima nesses meios de comunicação, interativos e virtuais, é capaz de interferir no processo de tomada de decisão e remodelar os artefatos cognitivos pessoais, devido ao aumento ou à restrição de informações por parte dos agentes. Por isso, de acordo com Schumpeter (1991), as finanças formam um dos melhores canais de acesso para estudar os mecanismos sociais. Em particular, ainda que não exclusivamente, as finanças permitem também investigar os mecanismos políticos. A fecundidade desse ponto de vista se revela justamente nos períodos de mudanças, quando o presente começa a morrer e a se transformar em algo novo.

\subsection{Implicações do processo de digitalização da Bolsa de Valores}

Superar seus próprios limites. Esta consiste talvez na principal motivação do ser humano ao longo de sua existência. Considerada fundamental, tal característica impele a humanidade a quebrar paradigmas e a buscar incessantemente, novas respostas. Sobre essa influência afirmam Souza e Cova (2009, p. 2): "Nas últimas décadas, não raro temos visto o supostamente impossível tornar-se trivial, graças à avassaladora velocidade com que as inovações tecnológicas invadem a sociedade. Nesse contexto, destaca-se o papel das ferramentas telemáticas".

Sob esse enfoque, e com o processo de inserção e disseminação das tecnologias de informação iniciado ao findar do século XX, a organização do trabalho sofre uma transformação radical, pois tais aparatos tecnológicos permitem (em alguns casos específicos) eliminar o trabalho físico e substituí-lo por comunicação, imagens e sistemas cibernéticos de autorregulação (RABINBACH, 1990). Para Tonelli (2003, p.38) "esse processo parece gerar uma nova mudança na concepção do tempo e do espaço no cotidiano do trabalho, levando a novos modelos de comportamento e à exigência de novas habilidades a serem exercidas no trabalho, o que inclui a flexibilidade”.

É possível asseverar, portanto, que a dimensão de tempo é relativa para cada pessoa e repleta de significados distintos no que tange à cultura e ao momento histórico em que é observada. No momento contemporâneo, o tempo tem sido caracterizado como veloz e de aceleração. Desse modo, a sofisticação e a combinação de hardwares e softwares robustos tornam cada vez mais rápidos e precisos os procedimentos de tratamento de dados e obtenção de respostas, sendo a internet um importante vetor para esse movimento de aceleração e disseminação da informação. O advento da tecnologia, por exemplo, foi capaz de afetar a percepção temporal e fez que a economia internacional, em especial os mercados financeiros, sentisse os reflexos dessa realidade (GORMAN e SINGH, 2009; PARDO-GUERRA, 2012).

O comportamento dos agentes operadores do mercado de ações é diferente em cada um dos períodos analisados, devido aos investimentos em tecnologias da informação. Esses avanços podem alterar as condições de tempo envolvidas no campo analítico das referidas atividades, permitindo fazer 
estimativas e inferências em espaços reduzidos de tempo. Sem embargo, o agente passa a dispor de ferramentas auxiliares para verificar, mensurar e, analisar os riscos mais importantes dos contratos. Os operadores passam, portanto, a utilizar todas as informações disponíveis para a projeção de estratégias funcionais, uma vez que suas ações e comportamentos dependem das "práticas sociais integrativas" (PREDA, 2001).

"Práticas sociais integrativas" é o termo empregado por Preda (2001) para determinar as condições que legitimam as leis sociais na bolsa de valores. Neste campo especificamente econômico, dotado de trade-off entre risco versus retorno, o autor identifica como processo de preparação, a generalização de um conjunto de discursos, práticas, modos de representação e semelhanças nos artefatos cognitivos. Assim, interpreta-se a bolsa de valores tal qual uma arena social e classifica-se o processo decisório dos agentes de interdependente.

A “performatividade" do mercado acionário, expressão utilizada por Callon (1998), diz respeito a um processo adaptativo, determinado com base em práticas e intervenções políticas capazes de dar autonomia à economia para modelagem de novas práticas, instituições e racionalidade dos agentes. As questões adaptativas surgem em meio à disseminação de artefatos e instrumentos que estruturam os novos mercados e assessoram os agentes na tomada de decisão. Elas se baseiam em princípios da teoria econômica e aproximam a realidade aos imagináveis modelos da ortodoxia econômica (CALLON, 1998). Os modelos de representação/visualização são funcionais na transformação de dados e transmissão de informações em uma dimensão temporal reduzida, por meio de imagens que agreguem todas as transações e as disseminem com aspectos claros, visíveis e inteligíveis a todos os agentes do mercado. Tal condição facilita a dinâmica dos ciclos dos contratos (compra e venda) e contribui tanto para a elaboração de estratégias quanto para as escolhas certas, de acordo com as condições humanas e não humanas dos agentes (PREDA, 2001).

Segundo Preda (2001), Knorr-Cettina e Brueger (2002), as ferramentas tecnológicas do mercado como base para a ocorrência da racionalidade interdependente, o momento de tomada de decisões de investimentos dos agentes pela interpretação matemática e perceptiva das expectativas comportamentais dos demais agentes do mercado, divulgadas pela configuração tecnológica do sistema Home Broker, no formato de dados, gráficos e informações tornam os agentes e os preços dos ativos previsíveis.

Em linhas gerais, os mercados financeiros, em consonância com as teorias tradicionais de finanças, são perfeitos e eficientes. Aliados ao paradigma central da racionalidade dos agentes econômicos, servem de substrato para a formulação dos principais modelos financeiros, partindo do pressuposto de que suas decisões são consistentes com o conceito de Utilidade Esperada (YOSHINAGA et al., 2004). Fama (1970) definiu que um mercado no qual os preços dos ativos sempre reflitam completamente todas as informações disponíveis é chamado de eficiente. Segundo Ross et al. (2002), nesses mercados, não há maneira de se obter lucros extraordinários com o uso das informações disponíveis, afinal os preços praticados já refletem o valor presente dos títulos. 
Com base em tal premissa, considerada elementar, a evolução das tecnologias informacionais foi, portanto, fundamental para trazer maior eficiência aos operadores desses mercados e proporcionar maior velocidade à troca de informações, o que, por conseguinte, ocasiona maior grau de confiabilidade.

Callon (1998), no entanto, amplifica o argumento inicialmente erigido por Granovetter (1985) - que investigou a estruturação de mercados e da própria ação econômica, com base em relações sociais (que também recebem o epíteto de redes de contatos) - e difunde a ideia central das chamadas "redes sociotécnicas", segundo as quais, mais do que interagir entre si, os agentes incorporam as tecnologias de que dispõem e esses artefatos tecnológicos amparam, ancoram e assessoram suas respectivas tomadas de decisão. Assim, as ações dos indivíduos em determinado mercado seriam influenciadas também por esse grupo de agências calculativas (complexo de condicionantes não humanos, isto é, tecnológicos, que afetam dados e informações capazes de impactar as operações desse indivíduo no mercado).

Esse efeito ocorrido na performance dos agentes investidores foi observado por Garcia-Parpet (2003), que pesquisou o processo de informatização dos leilões de morangos ocorridos na França, especificamente em Sologne, e concluiu que a adoção dessa ferramenta tecnológica informacional aproximou o pequeno mercado rural local dos sofisticados modelos de mercado da vertente econômica ortodoxa.

No Brasil, na mesma conjuntura de reformas e aperfeiçoamentos institucionais semeados pela introdução do Plano Real, na década de 1990, o mercado financeiro passou por uma gama extensa de inovações tecnológicas visando aperfeiçoar suas operações. Surgiram, pois, sistemas avançados, como Mega Bolsa, GTS, Web Trading e Home Broker. Contudo, o píncaro desse processo de avanço tecnológico consistiu na conexão, em 2010, da Bolsa de Valores de São Paulo, principal centro financeiro do país, aos outros mercados financeiros internacionais:

Um dia, há muitos anos atrás, o mercado financeiro do Brasil foi salvo pela cadeia de lojas Radio Shack. Essa é a história contada por François, presidente de uma companhia canadense de telecomunicações que, no começo do ano 2010, conectou a Bolsa de Valores de São Paulo com os mercados financeiros globais. Até esse momento, o mercado brasileiro estava ligado a outros mercados internacionais por telecomunicações convencionais: fios telefônicos de cobre, algumas conexões de satélite e redes públicas de internet. A velocidade desses sistemas era devagar demais para uma nova geração de investidores sofisticados para os quais o tempo no mercado é medido em milissegundos (milésimos de segundo) e até microssegundos (milionésima de segundo). Essa é a nova temporalidade do mercado internacional. O trabalho de François consistia em "alinhar" São Paulo com os tempos dos mercados globais, criando uma conexão veloz entre Brasil e os novos investidores europeus e norteamericanos. Mas, no dia em que a empresa de François iria se conectar com a Bovespa, os engenheiros encontraram um problema prático: os fios dos sistemas, feitos no Canadá, eram de uma espessura maior do que os fios do sistema da Bovespa. A conexão era fisicamente impossível. Assim, minutos antes da abertura do mercado, um engenheiro da equipe de François correu até uma loja de produtos eletrônicos perto da Bovespa procurando um adaptador especial. Assim, com vinte reais e um adaptador de Radio Shack, o Brasil entrou nos "mercados globais de alta velocidade" com um levíssimo atraso (PARDO-GUERRA, 2014, p.2). 
Ante tal realidade, fica evidente que os mercados financeiros não são meros espaços onde investidores transacionam instrumentos financeiros, em especial, ações. As bolsas de valores integram uma vasta e complexa ecologia global que abarca conhecimentos específicos, tecnologias diversas, regulamentações e princípios político-morais, pois, segundo Pardo-Guerra (2014, p. 2-3):

[...] conectar São Paulo com outros centros financeiros globais não era só um problema técnico a ser resolvido com fios e adaptadores especiais; o trabalho de François e seus engenheiros era também uma tarefa de articulação de tecnologias e regulamentações assim como parte de um projeto maior de materializar um ideal de mercado no mundo real; um mercado veloz, eficiente e global.

Nesse cenário de velocidade nos fluxos de ordens do mercado de capitais e de novos investidores buscando a bolsa de valores como alternativa de investimento (CHAGUE, DE-LOSSO e GIOVANNETTI, 2020), esta pesquisa pretende investigar: como os corretores de valores atuam no processo de comprar e vender ações nessa modalidade (bolsa digitalizada); de que maneira esses atores disseminam as informações; quais instrumentos eles utilizam para embasar seus atos decisórios, com ênfase nos laços sociais estabelecidos e no ferramental técnico aplicado nas operações.

\subsection{Cultura e características profissionais: os corretores de valores no Brasil}

Em face do célere desenvolvimento tecnológico e informacional, aludidos na seção anterior, nas décadas de 1960, 1970 e 1980, ocorreu um processo de formulação de teorias calcadas nas diretrizes da ortodoxia econômica, prevalecente à época, baseadas na ideia de "performatividade". A utilização de artefatos tecnológicos com a finalidade de rodar robustas equações, como aquelas que integram o modelo de precificação de opções, desenvolvido pelos economistas Black e Scholes, tornou-se um expoente nesse contexto, sendo, de fato, amplamente adotado pelos operadores dos mercados de capitais (MACKENZIE e MILLO, 2003).

A partir da década de 1980, novas correntes teóricas debruçam-se sobre essa temática, em especial as finanças comportamentais (que contradizem os pressupostos de mercados eficientes e a racionalidade ilimitada) e a "nova sociologia econômica" (mediante, principalmente, estudos etnográficos e qualitativos que discutem as características intrínsecas, culturais e diversos nuances e matizes que envolvem os mercados financeiros). Os preceitos de Fourcade e Healey (2007) preconizam que o plano de constituir um mercado é, sobretudo, um projeto moral e técnico, pois considera que todas as decisões de como serão as tecnologias, normas, regimentos, organização e velocidade que irão reger o mercado estão intimamente relacionadas com a constelação de poderes e interesses que estrutura o sistema financeiro brasileiro e global (PARDO-GUERRA, 2010a, 2010b e 2010c; PARDO-GUERRA, 2012).

Nesse vértice teórico, vale ressaltar que os pregões por meio de viva-voz precederam a informatização e passaram a atrair, desse modo, um número substancial de investigadores para a pesquisa etnográfica. Abolafia (2001), por exemplo, por meio de extensa análise em mercados distintos de Wall Street, constatou que a maioria dos operadores demonstrava certo nível de preocupação com relação à construção e à manutenção de confiança com seus clientes e pares de trabalho, o que, em certa medida, 
mitigava determinados atos “oportunísticos” em relação a esses dois agentes. Müller (2006) mergulhou no universo do pregão viva-voz da Bolsa de Valores de São Paulo, um ambiente enérgico e repleto de tensões, e notou a existência de ajuda mútua entre os operadores, cujas ações se concretizavam na socialização de prejuízos e no reconhecimento de falhas pessoais no processo de operação, para resguardar o vínculo com o cliente. Ambos os autores sublinham que, não obstante a constatação de solidariedade e confiança, casos de agressividade, rivalidade e cobrança entre operadores, clientes e gerentes de pregão também permeavam as relações.

Todavia, algumas indagações emergem na esteira desse cenário: com a introdução dos sistemas de informática e os avanços tecnológicos implementados no mercado financeiro brasileiro, os aspectos culturais relacionados às funções originais dos operadores e corretores de valores, foram preservados? As relações sociais em rede se dissiparam com a introdução da tela do computador, enquanto intermediário, ou recorrer aos laços sociais foi algo fortalecido na era digital?

Knorr-Cettina e Brueger (2002) realizaram uma pesquisa etnográfica em que recorreram às salas de negociação de três bancos globais, baseados em Zurique, e observaram alguns desses fatores, pois, com o computador passando a ser o principal elo entre investidor e operador, ocorreram alterações na dimensão temporal, nas relações sociais e nos níveis de subjetividade. Pardo-Guerra (2010) também investigou esse processo de automatização das corretoras de valores inglesas e a digitalização da London Stock Exchange, enfatizando as principais modificações ao longo desse processo histórico.

Avançando nessa seara, esta pesquisa tenciona, por meio de uma abordagem qualitativa, fazer bom uso da análise documental e da entrevista estruturada para focalizar a realidade brasileira. Com base nesses instrumentos, desenvolveu-se uma nuvem de palavras e uma sólida análise de sentimento, em um processo de decomposição dos principais tópicos destacados pelos corretores de valores ao longo da entrevista. Espera-se, portanto, contribuir com a consolidação da literatura acerca do mercado financeiro brasileiro, para além de Zaloom (2006), Preda (2009), Beunza e Millo (2014), e Godoy et al. (2018), os quais analisaram as situações de países isolados.

Transcendendo esses atributos, esta pesquisa volta-se para dois aspectos primordiais: verificar quais ferramentas financeiras e estatísticas prevalecem nas análises dos corretores (índices fundamentalistas, análise grafista ou algoritmos) e de que maneira esses profissionais lidam com diferentes conflitos, como por exemplo, ter de maximizar a rentabilidade dos clientes e a própria comissão de corretagem. Dessa feita, será possível concretizar uma análise cultural de um mercado definido pela proliferação de tecnologias (ZALOOM, 2006; BEUNZA e STARK, 2004; MUNIESA, 2003; PARDO-GUERRA, 2010a) e pela diminuição de relações sociais concretas (BEUNZA e MILLO, 2014).

\subsection{Os instrumentos financeiros na decisão de investimento: análise técnica e fundamentalista}

Com o aperfeiçoamento do mercado financeiro, surgiram ferramentas para auxiliar os corretores de valores e investidores em geral na tomada de decisão quanto a seus ativos financeiros. A análise fundamentalista e a análise técnica, por exemplo, existem há cerca de trinta e 100 anos, respectivamente 
(PINHEIRO, 2019). Esses instrumentos possibilitam aos corretores, e pessoas físicas interessadas em investimentos no mercado de capitais, calcular os valores inerentes dos ativos, tendo como base comparativa o preço de mercado para efetivar a decisão de compra ou venda. Permitem, além disso, capturar e julgar a performance histórica de preços desses ativos, bem como os volumes transacionados, dados considerados fundamentais para estimar a tendência e a concentração deles em determinado mercado (SCHROEDER et al., 2016).

Em suma, a análise fundamentalista tem como gênese o meio acadêmico, seus principais adeptos são administradores de fundos e investidores a longo prazo (PIOTROSKI, 2000; LOPES e GALDI, 2006; PINHEIRO, 2019). Em lado oposto, a análise técnica tem como origem o meio profissional do mercado financeiro e conta com uma vasta utilização por agentes com ação especuladora no mercado, especialmente os day traders (WINGER e FRASCA, 1995; BARROS, 2015).

O método fundamentalista tenciona avaliar se existe um valor real ou intrínseco que se relaciona de forma direta com o desempenho da firma, isto é, em última instância, almeja determinar qual o justo valor de uma ação (BODIE et al., 2001; PENMAN, 2004). Já a escola técnica tem como objetivo formar projeções sobre o comportamento da cotação das ações no curto prazo, com base nos padrões observados no desempenho passado do mercado (ROTELLA, 1992; BARROS, 2015).

Vale ressaltar que a análise fundamentalista se baseia em indicadores econômicos e financeiros (especialmente liquidez, rentabilidade, estrutura de capital ou níveis de endividamento, entre outros), o que permite comparar as empresas com outras do mesmo setor (benchmark), considerando também a conjuntura econômica e política do país (DAMODARAN, 2002; LOPES e GALDI, 2006; LAGIOIA, 2007; BEIRUTH et al., 2007; PINHEIRO, 2019).

Em contrapartida, a análise técnica tem três pilares primordiais, conforme Barros (2015):

\begin{abstract}
O primeiro é que o preço desconta tudo e o mais importante nisto é saber como será o movimento do preço para saber o "start" de compra/venda do ativo. Portanto, o preço pode armazenar nos gráficos vários fatores como, por exemplo, econômicos e políticos, mas para o autor todos estes dados estarão contidos no valor/preço da ação. Já o segundo princípio relata que o preço age por tendência, isto é, o preço acompanha as decisões dos acionistas, tanto positiva, quanto negativamente, ou vice-versa, originando as tendências ascendentes e descendentes. $O$ terceiro princípio abrange a parte emocional dos agentes que são movidos por perdas e ganhos, sendo representados por padrões que vão se repetindo no decorrer do tempo e quanto mais representados estes padrões, mais previsível é o mercado (BARROS, 2015, p.43-44).
\end{abstract}

A análise gráfica está contida no âmbito da análise técnica e é uma ferramenta muito utilizada por investidores e analistas de mercado que, por meio de figuras e formas, avaliam tendências de preços (alta, baixa ou lateral) e estimam o comportamento de um papel. Os principais gráficos utilizados nesse tipo de análise são: gráficos de volume, de linha, de barra, e, principalmente, o gráfico de candlesticks. Por meio dos gráficos pode-se confirmar uma tendência (continuidade) ou constatar que haverá reversão. Para isso, vários recursos são empregados às notações gráficas, tais como: figuras (flâmula ou bandeira, ombrocabeça-ombro, retângulo, triângulo simétrico, topo duplo, fundo duplo, entre outras), volume financeiro e linhas de suporte/resistência. Somam-se a isso outros instrumentos, como o cálculo de médias móveis, 
bandas de Bollinger, convergência e divergência (MACD), Índice de Força Relativa (IFR), e mais uma gama de ferramentas técnicas (YANG e SATCHELL, 2003).

Como ressalta Barros (2015, p.40), "essas diferenças entre as duas ferramentas são dadas pelo propósito de responder uma pergunta chave de cada método: por que adquirir certo ativo? E quando é o momento certo da compra/venda de determinado ativo?" Diante de tais indagações, esta pesquisa possibilitará compreender quais os instrumentos mais utilizados pelos corretores de valores no processo de decisão quanto à melhor alternativa de investimento em ações. Existe preferência por uma das técnicas de análise?

\section{Metodologia}

Para a execução desta pesquisa foram realizados os seguintes procedimentos metodológicos: i) análise documental e ii) entrevistas estruturadas, fonte primária que sustenta este artigo. A análise documental constitui uma técnica relevante na pesquisa qualitativa, pois permite complementar informações obtidas por meio de outras técnicas e perceber os principais fenômenos em torno do tema investigado (LÜDKE e ANDRÉ, 1986; LAVILLE e DIONE, 1999; LAMY, 2020). Neste trabalho, foi realizada uma acurada análise documental de fontes secundárias (principalmente a vasta documentação mantida pela B3, e artigos acadêmicos publicados em revistas especializadas nacionais e internacionais), para obtenção de dados relacionados à história da bolsa e às demais instituições financeiras (em especial as corretoras de valores).

A coleta de dados tem seu foco principal nas entrevistas realizadas em dez instituições financeiras (corretoras de valores, agências de investimentos e Assets), a saber: Mundinvest Corretora, XP Investimentos, Amaril Franklin Corretora, Ágora Investimentos (Bradesco), Sita Corretora, Guide Investimentos, Geraldo Corrêa Corretora, Banco Inter, Ativa Investimentos, Gradual Investimentos. O propósito central foi observar as práticas laborais e culturais dos investidores algorítmicos no Brasil, durante visitas intercaladas em um período de cinco meses, no ano de 2018. De acordo com Spradley (1979, p. 3) "o trabalho de campo é a marca da antropologia cultural" e viver a realidade a ser estudada envolve uma gama de ações, tais como: fazer perguntas, aprender linguagens e expressões, comer alimentos, até então, estranhos ao seu paladar, observar cerimônias, tomar notas de campo, entrevistar informantes e observar seus atos.

Nessas visitas, foi conduzido um total de vinte entrevistas com profissionais do mercado financeiro. Nesse tipo de abordagem, pode-se observar e compreender a prática dos profissionais com base no ponto de vista dos participantes, mediante as interpretações de si mesmos em certas interações simbólicas. Por questões éticas, os nomes dos participantes foram preservados, optando-se por designá-los com letras de A a T.

As perguntas que guiaram as entrevistas foram elaboradas com base no referencial teórico para abranger o máximo possível de informações. Os discursos desses agentes permitiram resgatar histórias 
relacionadas às recentes alterações ocorridas no mercado financeiro do Brasil e verificar de que maneira esses atores observaram as transformações tecnológicas e seus efeitos nas dimensões temporal e cultural.

Cabe ao observador manter a atenção e privilegiar os dados que realmente serão capazes de definir novos conceitos, ou que podem reforçar outros já observados. A análise dos dados começa pela revisão e transcrição de todas as vinte entrevistas realizadas, o que exige tempo e certo grau de interpretação (GIBBS, 2007). O grande volume de dados (transcrições, gravações e notas de campo) é uma característica da pesquisa qualitativa, um tipo de análise que busca melhorar e aperfeiçoar os dados, como ocorre particularmente com a codificação. Embora a codificação tenha o propósito (explícito) de reduzir os dados a alguns "tipos", para que possam ser contabilizados, é também uma forma de organizar e controlálos.

Dessa feita, a análise e o tratamento dos dados foram permeados pela análise de conteúdo (BARDIN, 2011; MOZZATO e GRZYBOVSKI, 2011), por meio da categorização dos resultados e do levantamento das unidades de investigação. As entrevistas e transcrições foram, portanto, codificadas em onze categorias estabelecidas pelo observador, são elas: i) experiência profissional; ii) governança corporativa; iii) análise técnica; iv) análise fundamentalista; v) network; vi) tomadas de decisão; vii) psicológico profissional; viii) assimetria informacional; ix) conflito de interesses; x) investidor; e xi) regras. Todas elas foram utilizadas como parâmetro na análise dos dados e serão apresentadas no Quadro 1, adiante.

As categorias foram detalhadas na análise de resultados e uma nuvem de palavras, com várias cores e tamanhos, foi gerada, com base no número de menções em determinado texto. A nuvem de palavras é uma estratégia de organização dos resultados que facilita a compreensão do leitor e auxilia no processo de tornar a informação sucinta e simplificada em uma única figura visual (PRAIS e ROSA, 2017; VASCONCELLOS-SILVA e JORGE, 2019; VILELA et al., 2020)

Para além disso, foi conduzida uma análise de sentimentos das entrevistas. Trata-se de uma nova tendência na análise de textos e discursos, pois transcende a mera detecção de tópicos e busca identificar a emoção por trás de um texto. Por isso, é também conhecida como mineração de opinião e IA de emoções (RAMOS e FREITAS, 2019; PESSANHA et al., 2020; DE SOUZA et al., 2021). Para tal efeito, foram utilizadas técnicas de processamento de linguagem natural (NLP), linguística computacional e mineração de texto, por meio de machine learning. Em linhas gerais, a abordagem lexical conecta as palavras de cada discurso com o sentimento que carregam, por meio do algoritmo utilizado, permitindo conhecer as emoções intrínsecas às entrevistas.

Cumpre elucidar que, para o tratamento dos dados coletados por meio das entrevistas, foram utilizados os softwares Atlas TI e Excel; para a nuvem de palavras e a análise de sentimentos, o software R. O Quadro 1 abaixo define cada uma das categorias elaboradas pelo observador: 
Quadro 1: Categorias utilizadas na codificação

\begin{tabular}{|c|c|}
\hline CATEGORIA & DEFINIÇÃO \\
\hline EXPERIÊNCIA PROFISSIONAL & $\begin{array}{l}\text { Oportunidades profissionais, educação, eventos de mercado, } \\
\text { qualquer termo que possa encaixar no ponto de qualificação do } \\
\text { profissional. }\end{array}$ \\
\hline GOVERNANÇA CORPORATIVA & $\begin{array}{l}\text { Estratégias admitidas por empresas e órgãos reguladores do } \\
\text { mercado, com o intuito de reduzir conflitos e fortalecer } \\
\text { conceitos (transparência, equidade, prestação de contas e } \\
\text { responsabilidade corporativa) que fortalecem a confiança e } \\
\text { ética dos agentes do mercado financeiro. }\end{array}$ \\
\hline ANÁLISE TÉCNICA & $\begin{array}{l}\text { Análise técnica ou grafista é a teoria fundamentada em } \\
\text { gráficos. Os gráficos refletem os movimentos passados do } \\
\text { mercado, e, pressupõem que o que já ocorreu pode ocorrer } \\
\text { novamente. }\end{array}$ \\
\hline ANÁLISE FUNDAMENTALISTA & $\begin{array}{c}\text { Análise fundamentalista é a teoria fundamentada nos valores e } \\
\text { na saúde financeira da empresa (análise de balanços } \\
\text { financeiros, DREs). Busca prever quais os valores e resultados } \\
\text { futuros das empresas. }\end{array}$ \\
\hline NETWORK & $\begin{array}{c}\text { Toda forma de relacionamentos, contatos, proximidade } \\
\text { pessoal que possa afetar e proporcionar ganhos de capital } \\
\text { social ao profissional. }\end{array}$ \\
\hline TOMADAS DE DECISÃO & $\begin{array}{c}\text { A capacidade de filtrar, analisar e escolher as informações } \\
\text { disponíveis e definir quais as melhores opções dentro de uma } \\
\text { cesta de ativos, utilizando como auxílio alguma estratégia de } \\
\text { apoio. }\end{array}$ \\
\hline PSICOLÓGICO PROFISSIONAL & $\begin{array}{l}\text { Qualquer momento de erros, riscos, pressão, euforia, ânimo, } \\
\text { descontrole ou sensação psicológica. }\end{array}$ \\
\hline ASSIMETRIA INFORMACIONAL & $\begin{array}{l}\text { Condição de desigualdade no mercado. Informação não } \\
\text { perfeita e mal distribuída entre os agentes do mercado. }\end{array}$ \\
\hline CONFLITO DE INTERESSES & $\begin{array}{l}\text { Momentos em que a tomada de decisão vai beneficiar um } \\
\text { agente em detrimento de outro. }\end{array}$ \\
\hline INVESTIDOR & Características dos investidores. \\
\hline REGRAS & $\begin{array}{l}\text { Regulamentações, ajustes tecnológicos e mudanças sistêmicas } \\
\text { que interferem no molde operacional do mercado. }\end{array}$ \\
\hline
\end{tabular}

Fonte: Elaborado pelos autores, 2021.

Os resultados, após tratamento dos dados em consonância com o Quadro 1, estão apresentados a seguir.

\section{Apresentação e análise de resultados}

O estudo estrutural e cultural do mercado financeiro na cidade de Belo Horizonte indicou que, especialmente nos últimos anos, ocorreram profundas transformações no mercado. A evolução e a criação de tecnologias voltadas para o mercado financeiro deram suporte para uma mudança severa no mundo das finanças, e o Brasil buscou acompanhar e se aproximar, cada dia mais, dos mercados internacionais. 
Se o conceito de plataforma aberta de investimentos é distante para investidores mais conservadores, para os mais arrojados, aqueles que buscam um retorno acima da média do mercado, inovar e conhecer os novos produtos financeiros tanto da B3 quanto de outras corretoras é um fator de grande relevância, uma vez que pode potencializar os ganhos e garantir uma parcela maior dentro das empresas das quais são sócios. Antes, quando tudo era mediado pelos pregões viva-voz, os intermediadores dos contratos eram os corretores de valores mobiliários, conhecidos nos Estados Unidos como brokers.

Àquela época, as bolsas de valores do Brasil eram ainda separadas e classificadas por região. Como principal fonte de recursos para as empresas, a maior bolsa do país era a de São Paulo, seguida da do Rio de Janeiro, das Bolsas de Valores de Minas Gerais, Espírito Santo e Brasília (BOVMESB) e da bolsa do Extremo Sul, em Porto Alegre, RS. Hoje, a situação é diferente e totalmente integrada à B3, a bolsa de valores oficial do Brasil. Com sede em São Paulo, a B3 distribui todos os recursos financeiros das empresas e atende às demandas dos investidores, intermediando, desse modo, as negociações de compra e venda do mercado.

As entrevistas realizadas neste trabalho se concentraram em agentes de investimento autônomos ligados a boutiques de investimento das corretoras disponíveis em Belo Horizonte. Nessa oportunidade, outras duas classes de profissionais do mercado financeiro também foram entrevistadas: os analistas de valores mobiliários e os gestores de carteiras de investimentos. De acordo com a codificação apresentada na metodologia deste artigo e conforme as entrevistas realizadas, nota-se, no discurso dos entrevistados, a prevalência de cinco categorias: i) tomada de decisão; ii) experiência profissional; iii) network, iv) análise técnica; e v) regras (vide Quadro 2).

Quadro 2: Contagem das categorias de codificação por meio do conteúdo das entrevistas

\begin{tabular}{|c|c|}
\hline Categoria & Número de vezes \\
\hline Tomada de decisão & 120 \\
\hline Experiência profissional & 76 \\
\hline Network & 55 \\
\hline Análise técnica & 51 \\
\hline Regras & 46 \\
\hline Investidores & 44 \\
\hline Conflito de interesses & 42 \\
\hline Análise fundamentalista & 40 \\
\hline Psicológico profissional & 28 \\
\hline Governança corporativa & 22 \\
\hline Assimetria informacional & 10 \\
\hline
\end{tabular}

Fonte: Resultados da pesquisa. 
Os resultados mostram que, nesse grupo profissional em questão, os entrevistados debruçaram-se mais sobre o processo de tomada de decisão. O trecho a seguir exemplifica uma situação citada de forma recorrente nas entrevistas:

\begin{abstract}
"Eu tenho diversos tipos de clientes, eu sempre gostei mais de pessoa física. (...) E tem cliente pessoa física que não quer nem saber, do que eu faço nas análises e tal, eu tomo a decisão para ele. Em outros casos, eu tomo as decisões em conjunto com o cliente. E tem umas que só o cliente manda. Então, quer dizer, eu tenho que mais ou menos contrabalancear isso aí, uns eu penso tudo, uns eu penso a metade, outros eu não penso nada, o que ele manda eu faço" (Entrevistado A).
\end{abstract}

Os corretores enfatizam a força da experiência profissional nesse mercado, principalmente quando se trata de impulsionar o feeling e a rápida percepção do cenário econômico e financeiro no processo decisório (experiência profissional). Relatam também suas respectivas capacidades de extrair informações disponíveis para, em seguida, definir quais os melhores ativos para investir os recursos dos clientes.

\begin{abstract}
"Ó, tem muito feeling, tem muito feeling. O operador tem muito feeling. O estudo é importante também para ter uma base com conhecimento, assim, do balanço das empresas, mas é acompanhar, acompanhar o dia a dia das empresas ... O dólar está caindo e deve cair mais, por isso, Suzano, Braskem, esses papeis Suzano, Fibria, esses papeis ligado ao dólar tende a cair mais um pouco. Esse é o tipo de conhecimento que a gente tem que ter, praticar e acompanhar. Eu não compraria a Usiminas, por que a empresa está quebrada, o minério melhora lá fora e até que melhora ela, mas eu tô achando que o papel está meio esticado. Sabe quanto custava uma Usiminas em dois mil e oito? Quarenta e dois reais, sabe quanto ela vale hoje, dois e trinta. Olha a quantidade que esse mercado caiu" (Entrevistado B).
\end{abstract}

A análise do perfil dos profissionais de investimento que compõem a amostra demonstra tratar-se de indivíduos experientes no segmento, com média de idade de 48 anos, cada qual com sua maneira de narrar fatos da profissão. Muitos entrevistados atuam na área desde o pregão viva-voz e não desistiram de continuar mesmo após a inserção de tecnologias e de mudanças extremas nas operações do mercado. A grande maioria relatou também já ter passagem por bancos e por outras corretoras de valores.

Os entrevistados creditam a capacidade para entender o mercado das corretoras e as transformações recentes do setor à longa experiência nesse ramo de atividade. O momento de ingressar em uma carreira no mercado financeiro se assemelha aos estudos de Granovetter (1985), pois observa-se quanto é importante e também incessante a busca por informações e parcerias internacionais nesse mercado. O caso do fundador da XP Investimentos, Guilherme Bechimol, mostra muito bem que as relações de proximidade, ou "sociedade em rede", colaboram e elevam os graus de reconhecimento no mercado, assim como explícitas por Grün (2004a e 2004b).

“É, essa aí vai virar banco agora. É um negócio violento... Começou, é uns caras que a gente conheceu aí, não, depois no meio do caminho entrou um investidor estrangeiro que botou duzentos milhões lá dentro. Então ela deve ter, ela chegou a ter em Belo Horizonte cinco escritórios...Agressivo. É um negócio de futuro, é um negócio que existe lá fora. É um varejão, então, o que ela faz." (Entrevistado C). 
"Então, a XP entendeu isto vendo o mercado mundial se evoluindo, ou eu entro neste jogo, ou vamos todos virar pó. E é isso que está acontecendo. Então ela conseguiu um grande fundo estrangeiro, que é um dos maiores fundos do mundo, que é a General Atlantis, entrou como sócia, investiu. E eles começaram a investir em tecnologia, porque para você criar esta plataforma aberta que é a XP, você precisa de tecnologia. Você precisa de grana, e o investimento em tecnologia é pesado. Então este fundo estrangeiro acreditou no Guilherme Bechimol, e a XP está virando este conglomerado tão grande que você está vendo e a tendência é continuar crescendo". (Entrevistado D).

A categoria network também foi relevante nas entrevistas e os resultados apontam a importância das relações de proximidade e do estabelecimento de contatos para obter informações sobre oportunidades no mercado financeiro. Tais informações não se transmitem por indicadores de preços (p) e salários (w), mas sim pelas relações sociais incrustadas nas experiências dos profissionais, em perfeita consonância com o que prevê Granovetter (1985). Os trechos das entrevistas abaixo ilustram com precisão a importância dessa rede de relacionamentos dos corretores no processo decisório de compra e venda de ações:

\begin{abstract}
"O que você acha? Tenho amigos no mercado de trinta anos. É uma coisa até saudável para você fazer mesmo, até para você chegar a um ponto, um denominador comum. Trocamos informações sobre investimentos, oportunidades de ações. A informação circula. Troco ideia com meus grafistas aqui, meus analistas de fundamento. As relações são canais importantes para ajudar na decisão, além da parte técnica, é claro" (Entrevistado E).

"A primeira parte que você perguntou, basicamente, o mercado é muito pequeno, o mercado de capitais brasileiro. Posso te falar que assim, todo mundo conhece todo mundo. Tem corretora em SP, tem em Porto Alegre, mas, conhecer todo mundo conhece. Temos até certa facilidade de ter contato, mas assim, regionalmente aqui em $\mathrm{BH}$, já teve vários profissionais, colegas que saíram da Amaril, foram para a Pichionni, da Pichionni foi para o Geraldo Corrêa, então a gente está em contato. Lá é bem antiga, assim como a Amaril, mas com relação a data de fundação eu não sei te informar. Mas trocamos ideias sim, igual, por exemplo, o Amaril conversa com todos os diretores das corretoras regionais aqui de $\mathrm{BH}$ ” (Entrevistado F).
\end{abstract}

Para além desses laços sociais, verifica-se clara distinção entre os profissionais do mercado no processo de decidir e investir, pois, em um primeiro momento, nota-se forte utilização da análise técnica pela grande maioria dos entrevistados. Esse tipo de estratégia define as trajetórias futuras dos ativos com base nos índices históricos (cotação e volume negociado de ações).

Tais índices são selecionados e aplicados a equações matemáticas temporais que estimam e preveem qual será a evolução de preços das ações, de acordo com as publicações de Bonaldi (2018). Os corretores de valores e entrevistados G e H, por exemplo, acreditam nas seguintes proposições: o mercado é perfeito; os preços são reais; o movimento de mercado é real e basta analisar os gráficos para estabelecer os preços médios, as tendências das curvas de juros e o crescimento do preço/ação. Verifica-se, portanto, que possuem um perfil de nível técnico e utilizam a análise gráfica como estratégia para a tomada de decisão.

“Tem que saber interpretar os candles com precisão e ver as sinalizações dos gráficos. Sem falar que várias medidas ajudam para confirmar uma tendência como, por exemplo, o volume. Olhar volume é fundamental na hora de confirmar o rompimento de uma linha de suporte ou resistência no gráfico. Entende?” (Entrevistado G). 


\begin{abstract}
"Todo dia o mercado é eufórico e o gráfico capta essas oscilações! Já aconteceram diversas coisas, igual você citou a vez do Collor, tivemos a questão do subprime, mas, isso depende da posição que você está, se você estiver muito comprado e tiver uma crise financeira você vai sentir mais, se você estiver praticamente menos posicionado, você não vai sentir quase nada. Porque você vai sentir a perda dos seus clientes. Então você só vai sentir isso se você tiver uma carteira grande posicionada. Ah, o mercado caiu $200 \%$, se eu não estiver posicionado pode cair até $500 \%$, não faz diferença nenhuma, entendeu. Tem gente que, ah, o mercado é ruim. Não, o mercado é bom todo dia, depende do que você faz. Se você está vendido no mercado e está caindo, para quem está comprado ele é ruim, mas para quem está vendido ele e ótimo". (Entrevistado $\mathrm{H})$.
\end{abstract}

Por outro lado e em menor número, alguns corretores tomam suas decisões com estratégias fundamentalistas e embasadas nas demonstrações contábeis trimestrais, semestrais e anuais das empresas. A análise fundamentalista define a saúde econômica e financeira da empresa por meio de índices contábeis e financeiros.

Os resultados obtidos demonstram que esses profissionais se utilizam de índices contábeis para, assim, interagir com as condições atuais de compra/venda das ações das empresas, resultando em índices fundamentalistas como relação entre Preço/Lucro por ação (P/L) e o Valor Patrimonial da Ação (VPA), calculado pela razão patrimônio das empresas e número de ações negociadas, assim como constatou Bonaldi (2018). Vale ressaltar que o próprio mercado estabelece parâmetros para efeitos de comparação desses índices (benchmark), como enfatiza o entrevistado I:

\begin{abstract}
“(...) O importante que você olha hoje é isso aqui. Dívida Líquida/Ebitda. Devia aqui, três vezes a geração de caixa. Aqui, deve doze vezes a geração de caixa. O banco que tem juízo, não empresta dinheiro para empresa a partir de quatro... Só essa empresa aqui que você gosta, olha. A dívida líquida da CEMIG era nove milhões (R\$ 9.000.000,00), está em quinze milhões ( $\mathrm{R} \$ 15.000 .000,00)$. Nessa época ela tinha um caixa de ( $\mathrm{R} \$ 4.500 .000,00)$, agora ela tem dois $(\mathrm{R} \$ 2.000 .000,00) \ldots$ A Dívida Líquida/Ebitda que era 1, foi para 5” (Entrevistado I).
\end{abstract}

Vê-se, portanto, que seguem atentos às mudanças normativas ocorridas e às novas regras. Vários entrevistados relataram "tem que ficar atento o tempo todo", "é ler tudo que a CVM divulga", "qualquer alteração de norma reguladora pode afetar o investimento", ações que vão de encontro a essa categoria de codificação. Ao analisar e alinhar as estratégias dos demais entrevistados, verifica-se que muitos admitiram não ter preferência por uma ou outra ferramenta. Fatores como governança corporativa empresarial e conjuntura econômica dos mercados nacional e internacional também interferem na resolução sobre quais investimentos são mais atrativos para determinado período. Segundo o entrevistado J:

"Ler jornais e mídias especializadas todos os dias, auxiliam neste processo. Inclusive, quando o mercado abre no Brasil, já é noite no Japão e na China. Ler sites com notícias de lá também ajudam no ajuste de posições logo pela manhã. Conhecer a solidez da empresa, o grau de governança corporativa praticado e o setor microeconômico que ela está inserida, também contribui para isto, sabe?” (Entrevistado J). 
Contudo, em uma pesquisa qualitativa, não se deve atentar apenas às diferenças entre os agentes, mas também às semelhanças entre eles. Conforme os relatos colhidos, os investidores confiam muito no trabalho dos corretores. Muitas vezes, são clientes há anos dessas mesmas corretoras.

"Eu tenho cliente que vai e opera na casa dele, ele sempre dá uma ligada: "eu estou fazendo isso, o que você acha"? E ele acredita em mim. Se eu falar para ele não fazer, ele não faz não. Mesmo ele querendo fazer, eu falo, acho que não deve fazer por causa disso. Você pensa e, se quiser fazer, faz; o dinheiro é seu. Mas, acho que você não deve fazer por causa disso e disso. Agora, quando ele vem e fala "o que você acha de eu fazer isso?", e eu falo "faz", ele fica bem mais tranquilo para tomar a decisão" (Entrevistado K).

Então é isso, o operador tem que saber de tudo, é um trem que, por exemplo, o cara é milionário chega e bota o dinheiro na sua mão, você tem que assumir. A melhor coisa que existe em um operador é a confiança, primeira coisa. O cara não precisa nem ser tão bem formado, ele tem que ser bem visto pelo cliente, tem de ter confiança nele, e a confiança é importantíssima, sempre. A moeda número um que a gente trabalha é essa aí: a confiança. Tem corretoras aí que tem cinquenta anos, essa aqui tem quarenta anos. Eu tenho cliente que há trinta e tantos anos é meu cliente. Quando eu era menino lá na Credial, um diretor falou assim: "atende esse povo aqui para mim”, eu tenho cinco, seis, eu tenho oito clientes que estão velhinhos já, que estão desde lá comigo (Entrevistado L).

No entanto, isso não elimina um conflito de interesse latente. Enquanto os investidores querem maximizar o valor de seus rendimentos com ações, os corretores querem maximizar seus ganhos com corretagem e performance. Mesmo que de forma sutil, essas questões foram, sim, levantadas pelos entrevistados. Todavia, eles suavizam os problemas dessa relação, embasados na ideia de que a decisão final de compra e venda do ativo parte do cliente-investidor, que, no máximo, eles podem subsidiá-los com as melhores informações e sugestões de operações.

“É justamente por isso que existe essa, essa segregação, você não pode administrar a carteira do cliente. Você tem sempre que ligar para ele, para passar, "olha, você está fazendo isso, a gente recomenda que compre isso, venda isso", justamente para tirar esse erro, diminuir... mas na verdade não diminui o conflito de interesses não, o conflito continua existindo, mas para inibir a prática de... Isso é um churning, não é?" (Entrevistado M).

"Para inibir essa prática, a corretora tem mecanismos para inibir isso, não deixar isso acontecer. Então, tem lá uma continha que eles fazem de giro da carteira para inibir o churning. E, é isso, mas assim, é uma coisa que vai mais da consciência do operador, do trader. Não adianta nada ele ficar girando um cliente, ficar gerando corretagem, o cara vai perder dinheiro, vai embora e acabou. (...) Não adianta, não adianta. Tem corretoras aí que quando foram criadas, começaram a fazer muito isso, e viram que não deu certo". (Entrevistado N).

Os entrevistados destacam também a necessidade de ter um psicológico preparado para lidar com as perdas e reforçam um princípio fundamental das finanças comportamentais: "a dor da perda é maior que o prazer do ganho", ou seja, os investidores preferem um ganho certo e sem assumir tantos riscos, mas quando estão perdendo assumem mais riscos, tentando mitigar as perdas (conceito de racionalidade limitada estudado por Kahneman e Tversky (1979), na Teoria do Prospecto). Inclusive, quando vão se referir às perdas usam uma expressão muito comum no mercado financeiro que é "tomar uma violinada", isto é, "perder muito dinheiro" em uma operação. 
A assimetria informacional pode ser enxergada pela clara dificuldade que os investidores têm em decidir como alocar a carteira de ativos. Por mais simples que pareça, a estratégia "buy and hold" ainda é considerada insuficiente por grande parte dos pequenos investidores no Brasil, que, ao alterarem suas posições diariamente, optam por correr riscos e elevam os custos de transação relativos à sua carteira total. Em suma, o pensamento de curto prazo não foi deixado de lado e garante uma alta liquidez para o mercado financeiro, garantindo o espaço para o mercado especulativo, sobretudo no mercado de derivativos.

\begin{abstract}
“(...) Tem cliente que opera todo dia, precisa comprar e precisa vender todo dia. Mas, a maioria sempre fez carteira para médio e longo prazo. Day-trade, exatamente, principalmente opção, eu não recomendo para ninguém, eu acho que nunca vi ninguém ganhar dinheiro com isso. Só perde. Ninguém conta quando perde, o pessoal gosta de contar vantagem, se você fizer as contas de quem mexe com opção, se não for uma venda coberta, de papel coberto, quem for trabalhar comprando e vendendo opção no day-trade, perde. Nunca vi ninguém ganhar no final (...) Eu falo com o cara, não mexe com opção. A não ser o seguinte, você compra o papel, para você se proteger você vende uma opção. Porque o negócio é o seguinte, a opção você chega e você opera 10000, você ganhou 2000, ganhou 20\%, maravilha! Aí você vai operar 20, para ganhar 40 , só que você opera 20 e perde 10 . Aí você vai operar 20 para recuperar os 10 que você perdeu, perde mais 5 . Aí você vai operar mais 10 e ganha 1000, daí a pouco você está perdendo 5 , no final todo mundo perde, nunca vi ninguém ganhar. A não ser assim, aquele que ganhou muito dinheiro com opção vendeu tudo em cima do mercado. Mas quem continuou tudo na opção, não ganha. Pelo menos comigo, porque eu falo que já vi, porque eu nunca orientei também comprar ou vender opção, a não ser que fosse opção coberta. Você compra papel e vende uma opção para poder proteger da queda do mercado" (Entrevistado O).
\end{abstract}

\footnotetext{
"Eu acho que é um vício. Acho que o pessoal fica com aquela adrenalina e quer fazer um, não vou falar que é um jogo, porque você está comprando uma opção, você está pensando mais no longo prazo, mas, nesse caso, o cara está comprando para poder vender mesmo e para ter um giro. Então assim, não vou chamar de jogo, mas adrenalina, o cara não consegue sair dela. Eu não recomendo isso para ninguém, se o cara vier falar comigo "eu quero comprar uma opção", eu digo "não mexe com isso é a primeira coisa que eu falo, no final você vai perder" (Entrevistado P).
}

As características culturais e de trabalho dos profissionais se aproximam e mantêm-se alinhadas a cada visita e entrevistas realizadas. Os gráficos nas telas dos computadores, o book de ofertas e o painel de cotações fazem parte da tecnologia admitida pelos profissionais, é a cultura e a 'forma' que estes analisam, aprendem e executam o seu cotidiano. Isso também foi observado por Preda (2001), Grün (2010 e 2013), Müller (2002, 2003, 2004 e 2005), Pardo-Guerra (2010a, 2010b, 2010c, 2012 e 2014), entre outros autores.

O produto desta pesquisa mostra que a tomada de decisão dos profissionais do mercado financeiro na cidade de Belo Horizonte é definida em uma circunstância na qual eles optam pelo investimento com base em análises de índices ou gráficos, cálculos matemáticos e estatísticos apoiados sobre as perspectivas de comportamento passado e futuro dos integrantes do mercado. Tal comportamento está expresso nas telas dos computadores e cria, como bem escrito por Knorr-Cettina e Brueger (2003), a racionalidade interdependente que é configurada pela tecnologia atual dos mercados em padrões internacionais, possibilitando a visibilidade e a transparência a todos os agentes presentes e atuantes nos mercados financeiros. 
Essa realidade pode ser ilustrada pelas estratégias dos operadores que, ao atingir uma linha de suporte', revertem suas vendas em compras, elevando os preços das ofertas de compra (registradas no book de ofertas), criando uma tendência de alta e inibindo a queda. Quando os preços reais de mercado se aproximam da resistência, eles realizam os lucros e vendem as ações a preços menores, decrescentes, pois, o lucro não pode escapar. Porém, nem todos são capazes de acompanhar esse mercado composto de papéis de alta liquidez e alta volatilidade, que proporcionam altos retornos e são considerados acima da média do mercado.

Esse movimento de mercado constitui um jogo de soma zero, isso significa que, se B ganhar, o agente $\mathrm{A}$ tem de perder. O fato de a bolsa estar conectando todos os agentes desse mercado torna-os interdependentes, isto é, os retornos de agentes são derivados das perdas de outros integrantes dessa sociedade em rede, conforme mostram Knorr-Cettina \& Brueger (2003), Hassoum (2005) e Preda (2009). Após codificar, analisar as entrevistas e esmiuçar os resultados, foi gerada uma nuvem de palavras com o intuito de observar quais expressões mais apareceram na pesquisa de campo, o que contribui também para compreender os temas discutidos com maior frequência nas entrevistas. A nuvem de palavras contém as cem palavras mais utilizadas, o que permite compreender e caracterizar de modo mais adequado o cotidiano dos agentes autônomos de investimento no mercado financeiro.

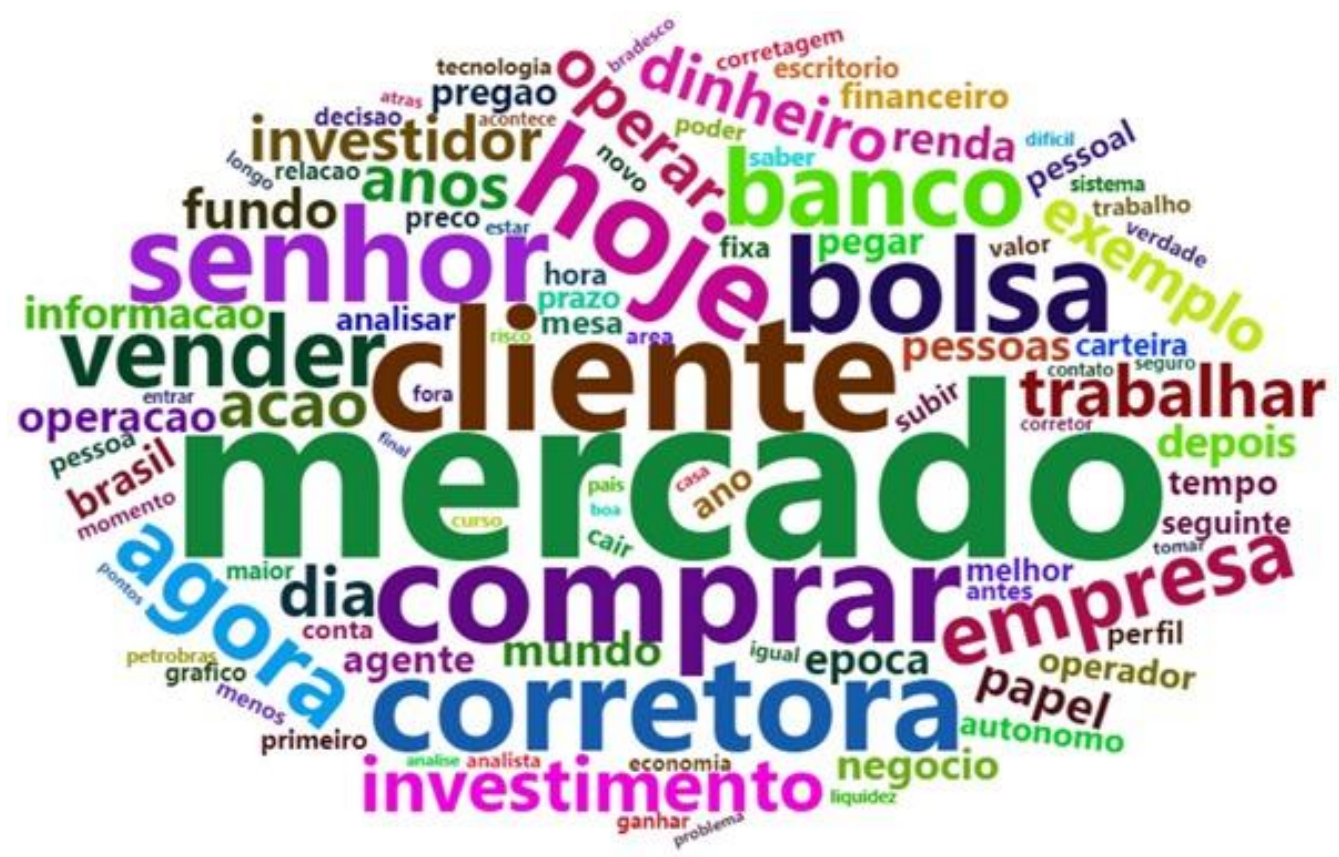

Figura 1: Nuvem de palavras com base no conteúdo das entrevistas.

Fonte: Resultados da pesquisa.

Nota-se que o vocabulário referente às finanças é frequentemente utilizado em todas as entrevistas para denominar instrumentos, atores e ações habituais do mercado financeiro. Há também o emprego de expressões temporais ao longo das entrevistas, o que evidencia uma narrativa em tom comparativo, uma vez que o entrevistador buscou conhecer as diferenças entre a realidade do pregão vivavoz e o cotidiano dos agentes após a inserção das tecnologias eletrônicas. Tal premissa se confirma com o alto número de repetições dos termos "hoje", "agora" e "exemplo", com 326, 243 e 149 aparições, 
respectivamente, devido à necessidade de exemplificar as mudanças ocorridas com o surgimento de tecnologias ou para lembrar de experiências passadas.

Destaca-se ademais o termo "senhor", que tanto pode servir de indicador etário (certamente os entrevistados eram consideravelmente mais velhos do que os entrevistadores), quanto de validação das antigas experiências dos entrevistados que viveram o modelo tradicional e presencial, e hoje convivem com o modelo tecnológico e semipresencial. À categoria tempo, seguem-se os termos "tecnologia" e "sistema", os quais apareceram cinquenta e cinco e cinquenta vezes cada um, respectivamente, e trazem consigo características do novo modelo empregado no mercado financeiro durante o século XXI.

É interessante compreender como o vocabulário das finanças é vasto e rotineiro nos diálogos. "Mercado" é o termo principal da nuvem de palavras das entrevistas, acumulando 576 aparições e restrito a uma única definição, o "mercado financeiro". Conforme se verifica no pensamento econômico, o mercado é constituído a começar do momento em que há a presença de atores dispostos a negociar, intermediários para institucionalizar os contratos e recursos comercializáveis que podem ser definidos como produtos. Desse modo, nota-se que os termos que seguem o "top 15" da nuvem de palavras estão totalmente associados aos conceitos que determinam o que é um mercado. "Cliente", por exemplo, aquele que compra; "corretora" e "banco", aqueles que vendem ou intermediam produtos financeiros; "comprar" e "vender", verbos que caracterizam as ações mais comuns nos negócios financeiros. O termo "bolsa", com 314 aparições, representa a B3, local onde são comercializados diferentes papéis. A palavra "papel" surge 122 vezes e "ação", 164.

Ainda no campo das finanças, fica evidente que conceitos importantes, como "risco", com 44 aparições e "liquidez", com 42, são pertinentes à discussão e estão associados aos demais termos utilizados no cotidiano dos agentes autônomos, como "fundo", "perfil", "carteira" e "decisão", afinal, a "análise" de risco, retorno e liquidez é fundamental para a definição dos termos indicados anteriormente.

Analisar uma nuvem de palavras não é uma tarefa trivial, visto que muitas vezes os termos podem ser utilizados em diferentes contextos e significados. As entrevistas mostram, por exemplo, que o termo "prazo" foi repetido 74 vezes ao longo das conversas, sendo que, em alguns momentos, falava-se do "curto prazo", em outros, do "longo prazo", ou até do prazo específico de um título qualquer. Isso também ocorreu com o termo "poder", que foi citado durante as conversas de três maneiras diferentes. Em uma, exprime a ideia de permissão, em que os agentes autônomos só poderiam operar a carteira do cliente com a autorização prévia e formal do mesmo. Em outra, mostra a possibilidade de algo ocorrer, dado que outro evento ocorreu. Já em uma terceira ocasião, a palavra foi utilizada no sentido de empoderar algum sujeito presente na discussão. O contrário também se verificou, ou seja, quando diferentes termos assumem o mesmo significado. Foi o que ocorreu com verbos como "pegar", "tomar" ou "entrar", que sempre remetem à ideia de compra de algum ativo para a carteira do corretor e, consequentemente, para a carteira da agência de investimentos.

Vale ressaltar a presença de termos comuns ao economês, como "investimento", "renda", "preço", "valor" e "economia", com 179, 110, 68, 62 e 53 aparições, respectivamente. Entre estes, se destaca o 
termo "renda". Empregado 69 vezes ao lado da palavra "fixa", indica produtos de renda fixa, aqueles com menor risco e mais atrativos para os investidores conservadores.

Outros termos bastante visíveis na nuvem de palavras são aqueles que remetem a atores e a lugares comuns aos entrevistados. "Empresa", "investidor", "agente", “autônomo", “analista", "Petrobrás", "Bradesco" e "corretor" representam nomes de alguns protagonistas do mercado financeiro brasileiro e sempre estarão vivos no vocabulário da classe financeira. Ademais, nas falas, surgiram expressões referentes a lugares como, por exemplo, "Brasil", "mundo", "escritório", "mesa" e "pregão". Isso ocorreu porque, muitas vezes, algum cenário macroeconômico ou uma experiência real foi discutida com praticamente todos os entrevistados.

Por fim, foi conduzida uma análise de sentimentos com base nos relatos dos entrevistados. A análise aponta dez indicadores de sentimentos: i) alegria; ii) antecipação; iii) confiança; iv) desgosto; v) medo; vi) negativo; vii) positivo; viii) raiva; ix) surpresa; e x) tristeza.

O sentimento negativo mostrou-se muito importante nessa análise. Tal indicador foi sinalizado devido à presença de entrevistados que trabalham em corretoras do modelo tradicional, que não tinham se adaptado ao novo modelo e estavam se descolando do novo varejo financeiro. Diante disso, um certo grau de pessimismo foi registrado.

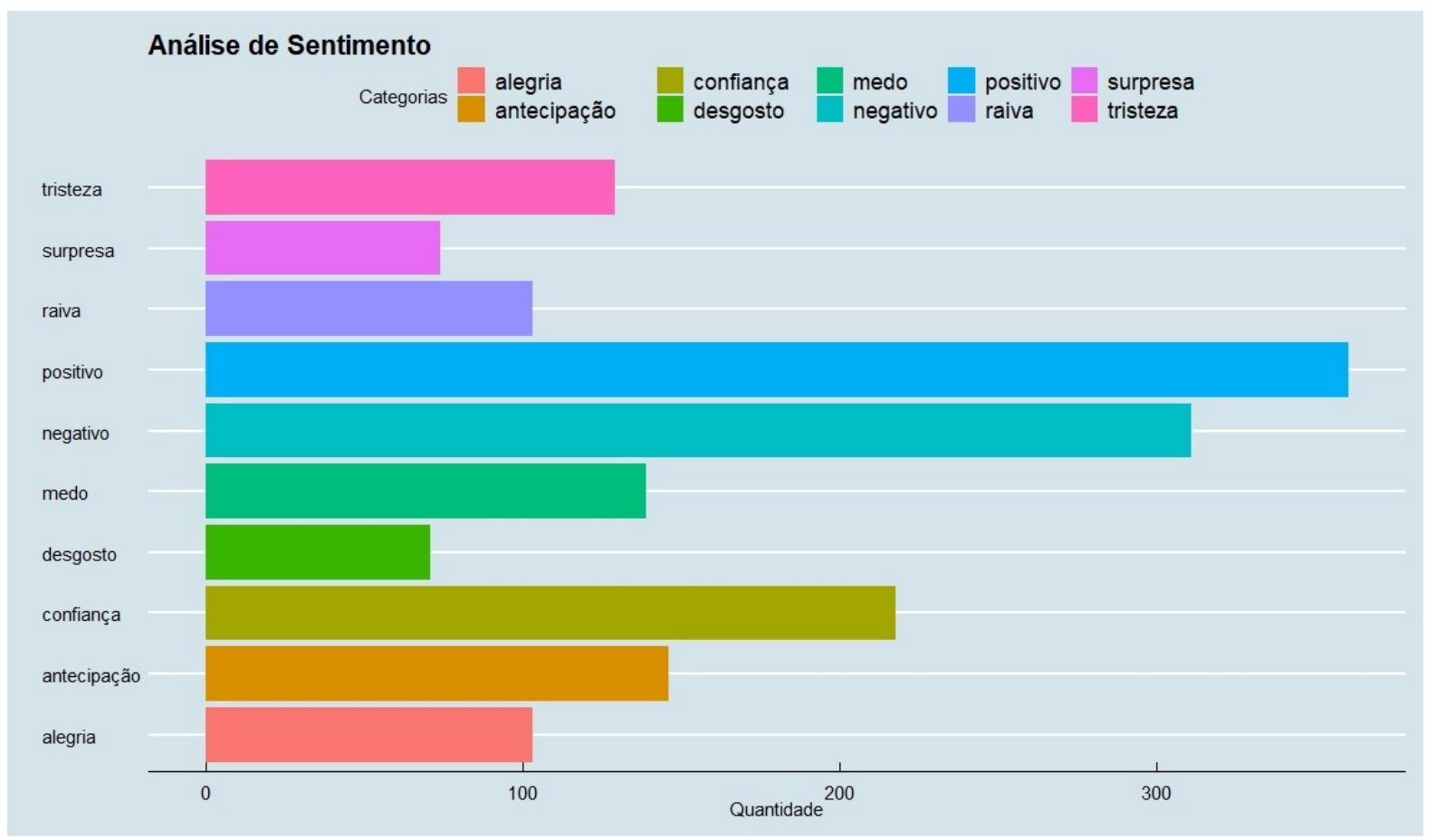

Gráfico 1: Análise de sentimentos do discurso das entrevistas.

Fonte: Resultados da pesquisa.

No geral, todos os entrevistados se mostraram muito qualificados, experientes e certos de quais são as suas funções enquanto especialistas na área de investimentos, seja o analista - aquele encarregado de compreender o cenário econômico e transmitir as informações para os traders de mesa e para o investidores, seja o agente autônomo - aquele responsável por comercializar os produtos financeiros da boutique de investimentos e acompanhar os clientes/investidores durante o processo de tomada de decisão

\begin{tabular}{l|c|c|c|c|c|c|c|c} 
Cadernos de Ciências Sociais Aplicadas & ano XVIII & vol. 18 & $n^{\circ} 32$ & págs. 21-50 & jul./dez. 2021 & UESB & Vitória da Conquista/BA & pág. 42 \\
\hline
\end{tabular}


de compra e venda de ativos. Dessa forma, percebe-se que o grau de confiança dos profissionais é alto após a adoção de mudanças tecnológicas que proporcionaram novas oportunidades de investimento ao mercado financeiro. Tais resultados convergem para a literatura internacional, que estuda os mercados financeiros segundo a ótica da sociologia financeira.

O processo de democratização do mercado de capitais de pessoa física no Brasil deve ser enxergado como um ganho para a sociedade brasileira. A redução dos custos para se investir, aliada à nova proposta de gerenciamento de investimento aplicada no Brasil após a inserção tecnológica, provocou um aumento acelerado no cadastro de pessoas físicas na B3 e, consequentemente, um aumento no número de corretores no Brasil. Tais fatores incitaram certo grau de otimismo no mercado nos últimos anos, sobretudo após as sucessivas quebras de recorde da B3, desde 2017. Para além disso, é importante ressaltar que o sentimento de antecipação dos atores do mercado foi relevante, dado que, em um momento de crescimento do número de investidores e de constantes mudanças tecnológicas no mercado financeiro, é exigida rápida adaptação tanto dos agentes autônomos quanto das corretoras, para não se perder espaço (market share) na excessiva concorrência do mercado financeiro.

Conclui-se, por fim, que esse movimento transformador foi muito importante para a construção social do mercado financeiro. Instituições até então pouco relevantes ganharam espaço, como, por exemplo, a Associação Nacional das Corretoras e Distribuidoras de Títulos e Valores Mobiliários, Câmbio e Mercadorias (ANCORD), responsável por certificar e regular a profissão dos agentes autônomos de investimento no Brasil, além de orientar os profissionais que intermediam os produtos financeiros com os investidores de pessoa física no Brasil. Nesse mesmo período, mais especificamente no ano de 2017, a Bolsa de Valores, Mercadorias e Futuros de São Paulo (BMF\&BOVESPA) fundiu-se com a Central de Custódia e de Liquidação Financeira de Títulos (CETIP), resultando na B3, a quinta maior Bolsa de Valores do mundo.

\section{Considerações finais}

Este trabalho teve como passo inicial aproximar o pesquisador da realidade atual dos mercados financeiros globais, de forma que este pudesse extrair os dados que condizem com o cotidiano cultural, operacional e tecnológico dos profissionais atuantes em uma das áreas das finanças sociais no Brasil. A pesquisa de campo foi praticada em dez diferentes corretoras da cidade de Belo Horizonte, MG, e conectadas à B3.

De caráter qualitativo, este estudo abarcou pesquisa documental e vinte entrevistas, para observar, desde os elementos mais relevantes e influentes no ingresso do profissional no setor financeiro, até as dificuldades recorrentes vivenciadas pelo profissional no mercado. Entre os resultados apontados, percebe-se a influência dos profissionais presentes no mercado sobre aqueles que estão mais próximos e com os quais têm alguma afinidade. Outra circunstância fundamental e expressiva são as experiências dos profissionais dos corretores de valores ao longo de suas carreiras, fato que os motiva de forma acentuada. 
Em muitas visitas, foi necessário conversar previamente com os gestores e sócios majoritários por meio de e-mails e contato telefônico. Em algumas situações, não se obteve resposta de alguns desses contatos, em outras, as respostas foram breves, sem, contudo, lograr êxito, o que dificultou a possibilidade de se aproximar dos profissionais da área. Episódios assim consolidam as evidências destacadas por outros autores e mostram como esse mercado é dinâmico, intenso e veloz. A cultura desses intermediadores é estritamente voltada para prática, eles se valem do uso das tecnologias disponíveis para captar uma grande quantidade de informações que devem ser analisadas, selecionadas e direcionadas, de acordo com o perfil de cada cliente, pois a decisão final é do próprio investidor.

Os resultados indicam forte poder das redes sociais estabelecidas, já que os profissionais atuantes nesse mercado exercem influência sobre aqueles que são mais próximos e com os quais possuem laços de afinidade, disponibilizando informações quanto à compra e venda de ativos. Dessa feita, deter conexões de relacionamento pode ser crucial no ato de decidir investir. Ademais, nota-se que o foco principal da tomada de decisão tem como subsídio a mera análise gráfica, relegando técnicas como a análise fundamentalista e estimações econométricas a um plano menor.

Nos dias atuais, novas regras e regulamentações de mercado poderiam inibir alguns costumes que infringiam a ética e geravam conflitos de interesses, os quais faziam parte da rotina dos corretores. Ao longo da pesquisa, buscou-se direcionar parte das entrevistas para esse tema, o que permite inferir que esses conflitos ainda existem e continuam a fazer parte das ações desses profissionais. De modo geral, nota-se que, como um bom corretor, o profissional objetivará também maximizar os valores auferidos com corretagem, indicando para os clientes "girar" a carteira e realizar novos investimentos, cabendo a este avaliar com critério a necessidade de "pivotar" repetidas vezes seu portfólio.

A nuvem de palavras evidenciou que os entrevistados comparam, de forma recorrente, nuances dos mercados financeiros eletrônicos atuais com os tempos de pregão viva-voz. Ademais, nota-se um vasto uso de expressões comuns ao mundo das finanças, ao habitat dos corretores de valores. Por outro lado, a análise de sentimentos permitiu conhecer as principais emoções que permeiam os discursos dos entrevistados. Observa-se prevalência do comportamento de animosidade entre corretores e investidores financeiros, uma vez que as entrevistas foram realizadas em um período de crescimento vertiginoso do número de atores do mercado financeiro e, por isso, sentimentos positivos foram substancialmente mais captados do que os demais.

É imperioso propor, para uma agenda de pesquisas futuras, estudos comparativos entre as novas instituições financeiras de investimento, as quais disseminam um novo conceito de mercado, mediante uma plataforma aberta de investimentos conectada a mercados internacionais e às antigas e tradicionais corretoras de valores dos anos de 1980 e 1990, com a finalidade de descobrir quais as diferenças e conflitos entre os profissionais de características e mentes diferentes.

Acredita-se que esta pesquisa tenha contribuído para uma melhor compreensão acerca do trabalho dos corretores de valores e a imersão nesse meio foi fundamental para esse fim. Apesar das dificuldades de marcar entrevistas e ser atendido pelos profissionais em questão, devido à dinâmica do mercado, que não para um segundo sequer, afinal qualquer tempo perdido pode significar uma boa oportunidade 
desperdiçada para auferir lucros, este estudo cumpriu com o seu propósito central, contribuir com uma visão qualitativa no que tange a um mercado permeado de análises matemáticas e quantitativas. Espera-se, portanto, fomentar outros debates no âmbito da "Nova Sociologia Econômica" no país, transpondo a análise das finanças para o campo social.

Por fim, vale apregoar que o intuito fulcral de entender os métodos dos profissionais tomadores de decisões que estão por trás das telas dos computadores realizando investimentos foi devidamente alcançado e traz contribuições importantes, principalmente porque esses corretores atuam em um segmento de forte expansão na economia brasileira. Até então, esse era um ramo que tinha como prática altas taxas de juros, levando a população a realizar investimentos em renda fixa. Com as quedas recentes na taxa básica de juros, os investidores assumem mais risco e buscam investimentos em renda variável, o que favorece o crescimento da bolsa de valores no país. Dessa feita, este estudo é relevante porque amplia as discussões e proporciona um nível maior de compreensão acerca desse setor repleto de nuances e culturalmente complexo.

\section{Referências}

ABOLAFIA, M. Making Markets: Restraintand Opportunism on Wall Street Cambridge, M.A.: Harvard University Press, 2001.

BARDIN, L. Análise de conteúdo. São Paulo: Edições 70. 2011.

BARROS, T.S. Ensaios em Board Interlocking. Tese apresentada à Escola de Administração de Empresas da Fundação Getúlio Vargas. São Paulo, 173 pgs, 2017.

BARROS, T.S. Análise Técnica e Fundamentalista: Ensaios Sobre Os Métodos de Análise. Revista de Administração e Negócios da Amazônia (Rara), V.7, n.2, mai/ago., 2015.

BEIRUTH, A.X. et al. Análise fundamentalista e avaliação de empresas: uma investigação teórica e um estudo de caso na Aracruz Celulose. Artigo apresentado no X Fórum de Ciências Contábeis do Espírito Santo. Aracruz, 01 a 03 de junho, 2007.

BEUNZA, D.; STARK, D. Tools of the trade: the socio-technology of arbitrage in a Wall Street trading room. Industrial and Corporate Change 13(2): 369-400, 2004.

BEUNZA, D.; MILLO, Y. Folding: integrating algorithms into the floor of the New York Stock Exchange. Manuscrito, 2014.

BODIE, Z.; KANE, A; MARCUS, A. Investments. 5.ed. Boston: McGraw-Hill, 2001.

BONALDI. E.V. O Pequeno Investidor na Bolsa de Valores: Uma Análise da Ação e da Cognição Econômica. Revista brasileira Ciências Sociais. vol.33 no.97 São Paulo, 2018.

BRENNAN, M.J. Corporate Finance Over the Last 25 Years. Michael J. Brennan. Financial Management, vol. 24, issue 2, 1995.

CALLON, M. The laws of the markets / edited by Michel Callon, Oxford ; Malden,

MA: Blackwell Publishers/Sociological Review, 1998.

\begin{tabular}{|l|l|l|l|l|l|l|c|c|}
\hline Cadernos de Ciências Sociais Aplicadas & ano XVIII & vol. 18 & $n^{\circ} 32$ & págs. 21-50 & jul./deそ: 2021 & UESB & Vitória da Conquista/BA & pág. 45 \\
\hline
\end{tabular}


CHAGUE F.; B. GIOVANNETTI. Day trading stocks for a living. Brazilian Review of Finance (Online), Rio de Janeiro, Vol. 18, No. 3, September 2020, pp. 1-4 ISSN 1679-0731, ISSN online 1984-5146, 2020.

CHAGUE, F.; DE-LOSSO, R.; GIOVANNETTI, B. Day Trading for a Living? Social Science Research Network (SSRN). Disponível em: http://dx.doi.org/10.2139/ssrn.3423101, 2020.

DAMODARAN, A. Investiment Valuation: Tools and Techniques for Determining the Value of Any Asset. 2 ed. New York: John Wiley \& Sons, 2002.

DE SOUZA, V. A.; FERREIRA DE SOUZA, E.; MEINERZ, G. V. Análise de sentimento em tempo real de notícias do mercado de ações, Brazilian Journal of Development, Vol 7, N 1, pp.11084-11091, 2021.

DIMSON, E.; MUSSAVIAN, M. Three Centuries of Asset Pricing. Journal of Banking and Finance, Vol 23, No 12, pp. 1745-1769, 1999.

FAMA, E. Efficient Capital Markets: A Review of Theory and Empirical Work. Journal of Finance. v. 25, p. 383-417, 1970.

FOURCADE, M; HEALY, K. Moral views of market society. Annual Reviewof Sociology, 33: 1-14, 2007.

GARCIA, M.-F. La Construction Sociale d'un Marché Parfait: Le Marché au Cadran de Fontaines-enSologne. Actes de la Recherche en Sciences Sociales, nº 65, pp. 2-13, 1986.

GARCIA-PARPET, M.F. A construção social de um mercado financeiro: o caso do Fontaine-en-sologne. Estudos de sociedade e agricultura. N.20, pp.5-44, 2003.

GIBBS, G. The Sage qualitative research kit. Analyzing qualitative data. Sage Publications Ltd, 2007.

GODOY, R.; SILVA, G.; FERREIRA, M.; ALVES, P.R.; SANCHES, A. análise comparativa para a escolha de Corretoras de Valores Mobiliários. Revista Científica Semana Acadêmica. Fortaleza, ano MMXVIII, No. 000141, 2018.

PESSANHA, G.R.G.; FIDELIS, T.O.; FREIRE, C.D.; SOARES, E.A. \#Fiqueemcasa: Análise De Sentimento Dos Usuários Do Twitter Em Relação Ao Covid19. HOLOS, [S.1.], v. 5, dez. ISSN 1807$1600,2020$.

GORMAN, M.; SINGH, N. Electronic Exchanges: The Global Transformation from Pits to Bits. Rotterdam: Elsevier, 2009.

GRANOVETTER, M. The strength of weak ties: a network theory revisited. In: Sociological Theory. Ed. Randall Collins. San Franciso, Califórnia, série Jossey-Bass, v.1. p.2001-2233, 1983.

GRANOVETTER, M. Economic action and social structure: the problem of embeddedness. American Journal of Sociology. Chicago: Universidade de Chicago, n.91, p.481-510, nov, 1985.

GRÜN, R. A dominação financeira no Brasil contemporâneo’. Tempo Social 25: 179-213, 2013.

GRÜN, R. A crise financeira, a guerra cultural e as transformações do espaço econômico. Brasileiro em 2009’. Dados 53: 255-297, 2010.

GRÜN, R. A evolução do espaço financeiro no Brasil. Revista de Ciencias Sociais, Rio de Janeiro, Vol. 47, nº1, 2004, pp. 5 a 47, 2004a.

GRÜN, R. A sociologia das finanças e a nova geografia do poder no Brasil. Tempo Social Vol. 16, No 2 pp. 151 a $176,2004 b$. 
GUILLÉN, M.F. Corporate Governance and Globalization: is there convergence across countries? Advances in Comparative International Management, 13: 175-204, 2000.

GUILLÉN, M.F. Models of Managements: work, authority, and organization in a comparative perspective. Chicago, University of Chicago Press, 1994.

HASSOUM, J.P. Emotions on the trading floor: social and symbolic expressions. In Knorr-Cetina e Preda, eds, The Sociology of Financial Markets. Oxford: Oxford University Press, pp.102-120, 2005.

HIRSCH, P.; FRIEDMAN, R. Clean Models vs. Dirty Hands: why economics is different from sociology. In: DIMAGGIO, P. (ed.). Structures of capital: the social organization of the economy. Nova York: Cambridge University Press, pp.39-56, 1990.

HOLLINGSWORTH, J.R.; BOYER, R. Contemporary Capitalism: the embeddedness of institutions. Cambridge/New York, 1997.

JENSEN, M.C. Value Maximization, Stakeholder Theory, and the Corporate Objective Function.Journal of Applied Corporate Finance, v.14, n.3, pp 8-21, 2001.

KAHNEMAN, D.; TVERSKY, A. Prospect theory: An analysis of decisions under risk. Econometrica, v. 47, n. 2, p. 263-292, 1979.

KNORR-CETINA, K.; BRUEGGER, U. Global Microstructures: The Virtual

Societies of Financial Markets, The American Journal of Sociology 107(4): 905-950, 2002.

LAGIOIA, U.C. Fundamentos do Mercado de Capitais. São Paulo: Atlas, 2007.

LAMY, M. Metodologia da pesquisa: técnicas de investigação, argumentação e redação. São Paulo: Matrioska Editora, 2020.

LAVILLE, C.; DIONE, J. A construção do saber: manual de metodologia em ciências humanas. Porto Alegre: Artmed, 1999.

LOBÃO, J. Finanças Comportamentais: Quando a Economia encontra a Psicologia. Actual Editora, 2018.

LOPES, A,B.; GALDI, F. C. Financial Statement Analysis also separate Winners from Losers in Brazil. Anais. Seminario de pesquisa econômica da EFGE/FGV, Realizado na USP, 2006.

LÜDKE, M.; ANDRÉ, M. E. D. A. Pesquisa em Educação: Abordagens Qualitativas. São Paulo: Ed. Pedagógica e Universitária-EPU, 1986.

MACKENZIE, D. The Credit Crisis as a Problem in the Sociology of Knowledge, American Journal of Sociology 116(6): 1778-1841, 2011a.

MACKENZIE, D. How to Make Money in Microseconds, London Review of Books 33(10): 16, $2011 \mathrm{~b}$.

MACKENZIE, D.; MILLO, Y. Constructing a Market, Performing Theory: The

Historical Sociology of a Financial Derivatives Exchange, American Journal of Sociology 109(1): 107-145, 2003.

MAURER, B. Mutual Life, Limited: Islamic Banking, Alternative Currencies, Lateral Reason Princeton University Press (Princeton), 2005.

MIYAZAKI, H. Arbitraging Japan: Dreams of Capitalism at the End of Finance.Berkeley: University of California Press, 2013. 
MOZZATO, A. R.; GRZYBOVSKI, D. Análise de conteúdo como técnica de análise de dados qualitativos no campo da administração: potencial e desafios. RAC, Curitiba, v. 15, n. 4, pp. 731-747, 2011.

MÜLLER, L. H. A. Mercado exemplar: um estudo antropológico sobre a Bolsa de Valores. Porto Alegre: Zouk, 2006.

MÜLLER, L. H. A. Caminhos e sentidos da informação no mercado de ações. Política \& Sociedade, 6(6): 133-164, 2005.

MÜLLER, L. H. A. Justo preço: uma etnografia da Bovespa. Idéias, 11, (3): 29-68, 2004.

MÜLLER, L. H. A. Livre Mercado. Civitas: Revista de Ciências Sociais 3(2): 301-326, 2003.

MÜLLER, L. H. A. Economicus \& Ludens: lógicas do pensar e agir humanos no universo do mercado de capitais. Sociedade em Debate 8(2): 02-43, 2002.

MUNIESA, F. Des marches comme algorithmes: sociologie de lacotation électronique à laBourse de Paris CSI, Vol. PhD, Paris: Ecoledes Mines de Paris, 2003.

PARDO-GUERRA, J. P. The Automated House: The Digitalization of the London Stock Exchange, 1955-1990, em B. Batiz-Lazo, J. C. Maixé-Altés and P. Thomes (eds) Technological Innovation in Retail Finance: International Historical Perspectives, London: Routledge, 2010a.

PARDO-GUERRA, J. P. Computerising gentlemen: the automation of the London Stock Exchange, c. 1945-1995 Science Studies Unit,. PhD in Science and Technology Studies, Edinburgh: University of Edinburgh, 2010b.

PARDO-GUERRA, J. P. Creating flows of interpersonal bits: the automation of the London Stock Exchange, 1955-1990, Economy and Society 39(1): 84-109, 2010c.

PARDO-GUERRA, J. P. Financial automation: past, present and future, in K. Knorr Cetina and A. Preda (eds) The Oxford Handbook of the Sociology of Finance, Oxford: Oxford University Press, 2012.

PARDO-GUERRA, J. P. Mercados financeiros, infraestruturas eletrônicas e culturas digitais no Brasil, 1980-2014. Projeto de pesquisa apresentado à Universidade Federal de Rio de Janeiro: Museu Nacional, Pós-Graduação em Antropologia, 2014.

PENMAN, S. H. Financial statement analysis and security valuation. 2. ed. Boston: Irwin Mc Graw Hill, 2004.

PINHEIRO, J. Mercado de Capitais: Fundamentos e Técnicas. 9ª ed. São Paulo: Atlas, 2019.

PIOTROSKI, J D. Discussion of separating winners from losers among low book-to- market stocks using financial statement analysis. Journal of Accounting Research, vol 10, 2005.

POLANYI, K. The Great Transformation: The Political and Economic Origins of our Time. Boston, Beacon Press, 2001.

PRAIS, J. L. S.; ROSA, V. F. Nuvem de palavras e mapa conceitual: estratégias e recursos tecnológicos na prática pedagógica. Nuances: estudos sobre Educação, 28(1), 201- 219. DOI:

10.14572/nuances.v28i1.4833, 2017.

PREDA, A. The Enchanted Grove: Financial Conversations and the Marketplace in England and France in the 18th Century. Journal of Historical Sociology 14(3):276-307, 2001.

PREDA, A. Framing finance: the boundaries of markets and modern capitalism, Chicago: University of Chicago Press, 2009.

PREDA, A.; KNORR-CETINA, K. The Oxford Handbook of the Sociology of 
Finance, Oxford University Press (Oxford), 2012.

RABINBACH, A. The human motor: energy, fatigue, and the origins of modernity. Berkeley: University of California Press, 1990.

RAMOS, B.; FREITAS, C. "Sentimento de quê?": uma lista de sentimentos para a Análise de Sentimentos. In: STIL 2019 - The 12th Brazilian Symposium in Information and Human Language Technology, Salvador, BA, Brazil, October, 15-18, 2019. [S.1.: s.n.], 2019.

RAUD-MATTEDI, C. Análise Crítica da Sociologia Econômica de Mark Granovetter: os limites de uma leitura de mercado em termos de redes e imbricação. Politica \& Sociedade, 6: 59-82, 2005.

ROSS, S. A.; WESTERFIELD, R. W.; JAFFE, J. Administração Financeira: Corporate Finance. 2. ed. São Paulo: Atlas, 2002.

ROTELLA, R. P. The Elements of Successful Trading, New York: Institute of Finance Simon \& Schuster, 1992.

SCHROEDER, R.G.; CLARK, M.W.; e CATHEY, J.M. Financial accounting Theory and Analysis: text reading and cases. $12^{\mathrm{a}}$ ed. USA: Willey, 2016.

SCHUMPETER, J.A. The Economics and Sociology of Capitalism. Princeton, NJ, Princeton University Press, 1991.

SMELSER, N. J. A sociologia da vida econômica. 1 ed. São Paulo: Enio Matheus Guazzelli \& Cia. Ltda, 1963.

SPRADLEY, J.P. The Ethnographic Interview. New York: Holt, Rinehart and Winston, 1979.

SOUZA, M.; COVA, C. Os impactos da introdução do home-broker no mercao de valores mobiliários brasileiro. V Congresso Nacional de Excelência em Gestão, 2009.

STEINER, T. A Sociologia Econômica, São Paulo: Atlas, 2006.

STREECK, W.; CROUCH, C. Political Economy of Modern Capitalism: Mapping Convergence and Diversity. London/California, Thousand Oaks/Sage, 1997.

THALER, R. The Winner's Curse: Paradoxes and Anomalies of Economic Life. New York: Free Press, 1991.

THALER, R. Misbehaving: The Making of Behavioral Economics. New York: W.W. Norton, 2015.

THALER, R.; SUNSTEIN, C.R. Nudge: Improving Decisions on Health, Wealth, and Happiness. New Haven, CT: Yale University Press, 2008.

TONELLI, M.J. Produção de sentidos: tempo e velocidade nas organizações. Revista de Adminisração Pública, RAP. V.37, n.1, p.33-50, 2003.

VASCONCELLOS-SILVA, P.V.; JORGE, T. Análise de conteúdo por meio de nuvem de palavras de postagens em comunidades virtuais: novas perspectivas e resultados preliminares, VIII Congresso IberoAmericano de Investigação Qualitativa (CIAIQ2019), volume 2, 2019.

VILELA, R. B.; RIBEIRO, A.; BATISTA, N. A. Nuvem de palavras como ferramenta de análise de conteúdo: uma aplicação aos desafios do ensino no mestrado profissional. Millenium, 2(11), 29- 36. DOI: https://doi.org/10.29352/mill0211.03.00230, 2020.

WILLIAMSON, O. E. Comparative economic organization: The analysis of discrete structural alternatives. Administrative Science Quarterly, 36, 1991. 
WILLIAMSON, O. E. Markets and hierarchies: Analysis and antitrust implications: A study in the economics of internal organizations. New York: Free Press, Macmillan, 1975.

WILLIAMSON, O.E. Corporate Finance and Corporate governance. Journal of Finance, v. 42, n. 3, p. 567-591, 1988.

WINGER, B.; FRASCA, R. Investments: Introduction to analysis and Planning, 3. ed. Englewood Cliffs: Prentice Hall,1995.

YOSHINAGA, C. E; OLIVEIRA, R. F; SILVEIRA, A. D. M.; BARROS, L.A.B.C. Finanças comportamentais: uma introdução. Revista de Gestão da USP, São Paulo, v.15, n.3, p. 25-35, julhosetembro, 2008.

ZALOOM, C. Out of the pits: traders and technology from Chicago to London. Chicago: Chicago University Press, 2006. 